implies confusion about what natural populations are. All the phenomena I discussed in my review (except in the extreme examples where hybrids are completely sterile) involve sets of individuals selected for different properties but exchanging genes to some extent. To the extent that they exchange genes they must be regarded as parts of one interbreeding population under disruptive selection.

Finally I think that Mather's use of " disruptive " to describe this type of selection is justifiable. Disrupting the population is precisely what it " tries" to do. What prevents it from doing so, in the conditions in which it leads instead to polymorphism, is not a matter of the kind of selection. It fails to disrupt (that is to split) the population if its intensity or persistence is inadequate, if the necessary genetic variance is not available, or if the breeding system holds the parts of the population together. The various laboratory experiments that have been done using disruptive selection have had very different results. The differences do not depend on differences of the type of selection, but on the mating systems used, that is on the population stucture imposed or allowed to develop. It would be wrong so to define disruptive selection that the definition depended more on the breeding structure than on the selection itself.

\title{
REFERENGES
}

FISHer, R. A. 1930. The Genetical Theory of Natural Selection. Clarendon Press, Oxford. MATHER, K. 1953. The genetical structure of populations. Symp. Soc. exp. Biol., 7, 66-95. MATHER, K. 1955. Polymorphisms as an outcome of disruptive selection. Evolution, 9, 52-61. MAYr, E. 1974. The definition of the term disruptive selection. Heredity, 32, 404-406.

simpson, G. G. 1944. Tempo and Mode in Evolution. Columbia University Press, New York. thoday, J. M. 1972. Review Lecture: Disruptive selection. Proc. Roy. Soc. Lond. B., 182, 109-143.

\section{A GENE INVOLVED IN LYSINE EXCRETION IN ESCHERICHIA COLI K12}

SUSAN J. JENKINS,* CAROLYN A. SPARKES and M. C. JONES-MORTIMER†

Department of Genetics, University of Birminghom, PO Box 363, Birmingham B15 2TT

Received 14.i.74

\section{SUMMARY}

One of our laboratory strains of Escherichia coli $\mathrm{K} 12$ carries an allele, lys $X$, which permits the excretion of lysine. Other strains do not carry this allele. The lys $X$ gene maps on the side of $\arg A$ distal to $\operatorname{thy} A$, at about 53.5 minutes. In partial diploids the $l y s X$ allele is recessive to the $l y s X^{+}$(non-excretor) allele.

\section{Introduction}

Mutants of Escherichia coli have frequently been observed to overproduce and excrete normal metabolites. In a series of transduction experiments

* Present address: Waverley School, Hobmoor Road, Birmingham.

$\dagger$ Present address: Department of Biochemistry, The University, Leicester LE1 7RH. 
with the lysine auxotroph JM239 it was observed that some, but not all, of the Lys ${ }^{+}$recombinants were surrounded by haloes due to growth of the background of the recipient. Since the recipient strain used responds to lysine but not to pyridoxine (i.e. it is a lys $A$ and not a lys $B$ mutant-Bukhari and Taylor, 1971) we presume that the phenomenon is indeed one of lysine excretion, and is due to a gene cotransducible with lys $A$. This communication describes the location of a gene involved in lysine excretion and shows that the non-excretor allele is dominant to the excretor allele. The gene has been named lys $X$ and the dominant non-excretor allele is assumed to be lys $X^{+}$.

\section{Materials AND METhodS}

The minimal medium used was that of Smith (1961) supplemented as required with thymine $(60 \mu \mathrm{g} / \mathrm{ml})$, lysine $(80 \mu \mathrm{g} / \mathrm{ml})$ other amino acids $(20 \mu \mathrm{g} / \mathrm{ml})$ or pyridoxine $(2 \mu \mathrm{g} / \mathrm{ml})$. Glucose $(0.4$ per cent $)$ was used as the carbon source. Oxoid nutrient agar and oxoid nutrient broth were routinely supplemented with thymine $(60 \mu \mathrm{g} / \mathrm{ml})$. Plkc transduction was carried out as described by Miller (1972).

Lysine excretion was tested by streaking cultures on suitably supplemented minimal agar medium into which about $10^{2} \mathrm{cells} / \mathrm{ml}$ of a lysine auxotroph had been incorporated. (Overnight broth cultures of strain JM 238 were harvested and resuspended in iso-osmotic saline for this purpose.)

Table 1 lists the strains used. All incubations were at $37^{\circ}$.

TABLE 1

Strains of E. coli $K 12$

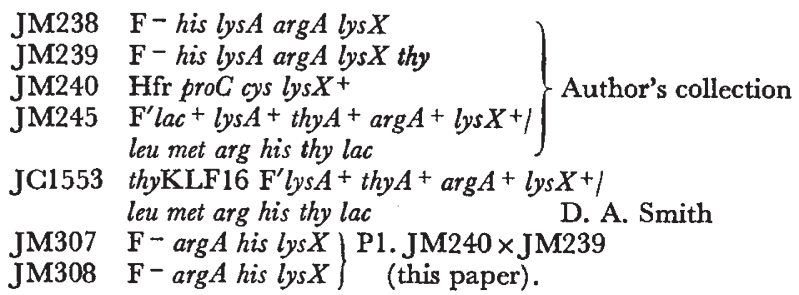

The gene symbols are those employed by Taylor and Trotter (1972) except lys $X$ which is here used to denote a gene involved in lysine excretion.

\section{Results}

(i) Location of lys X

P1kc propagated on $\mathrm{Jm} 240$ (lys $X^{+}$) was used to transduce JM239 (his lys $A$ thy $A \arg A$ lys $X$ ) and $\mathrm{Lys}^{+}$recombinants were selected. Five hundred and eighty-five colonies were picked at random and scored for their ability to excrete lysine and for their arginine and thymine requirements. The results of the experiment are given in table 2 . These data are consistent only with the gene order

$$
\text { lys } A \text { thy } A \arg A \text { lys } X \text {. }
$$

Strains JM307 and JM308 are single colony isolates of genotype lys $A^{+}$ thy $A^{+} \arg A$ lys $X$ derived from this cross. 


\section{(ii) Dominance of lys $\mathrm{X}^{+}$}

Strains JM307 and JM308 were mated with the $\mathrm{F}^{\prime}$ donors JM245 and JC1553thy KLFl6 by streaking the donors on lawns of the recipients on plates supplemented with histidine, to select $\mathrm{Arg}^{+}$progeny. Single colony isolates were made from two colonies from each cross, and tested for their ability to excrete lysine. None did so. These putatively diploid strains were grown up overnight in nutrient broth, streaked out on nutrient agar plates and, after overnight incubation, replica plated on to histidine minimal

TABLE 2

Analysis of the lysA + transductants from the cross between $7 M 240$ (lysX+) and 7 M239 (lys A thyA argA lysX)

\begin{tabular}{|c|c|c|c|c|}
\hline thy $A$ & $\arg A$ & lys $X$ & $\begin{array}{l}\text { Number } \\
\text { obtained }\end{array}$ & \\
\hline+ & + & + & 74 & \multirow{4}{*}{2 cross-overs } \\
\hline- & - & - & 371 & \\
\hline+ & - & - & 110 & \\
\hline+ & + & - & 16 & \\
\hline - & - & + & 8 & \multirow{5}{*}{4 cross-overs } \\
\hline - & + & - & 0 & \\
\hline+ & - & + & 2 & \\
\hline \multirow[t]{2}{*}{-} & + & + & 4 & \\
\hline & & Total & 585 & \\
\hline
\end{tabular}

medium. About 1 per cent of the colonies failed to grow on the replica plate (and have therefore lost their episome). These were shown to be arginine auxotrophs and to have regained the ability to excrete lysine. We therefore conclude that both these episomes carry the dominant lys $X^{+}$allele, which prevents the excretion of lysine.

\section{Discussion}

The lysine auxotroph JM239 is of course unable to excrete lysine, but those of the $l y s^{+}$strains which we tested which carried the same $\arg A$ allele as JM239, share with the lys $A^{+}$recombinants JM307 and JM308 the property of being able to excrete lysine. It thus appears that the lys $X$ allele is present in our original $\arg A$ strain (22A43, obtained from $\operatorname{Dr} \mathrm{S}$. Baumberg). In this property these strains differ from other nominally wild type strains such as JM240 (a derivative of W1485) and the Hfr strains (TORI3 and AB2297) from which the episomes employed in these experiments were derived.

In view of the large number of ways in which a recessive mutation can lead to the loss of regulation of a biosynthetic pathway (for a review see Brenner and Ames, 1971), it is impossible at present to suggest the precise biochemical nature of the lesion in our strains, but it is expected that their further investigation will shed light on the control of lysine biosynthesis in E. coli.

These experiments were carried out by S. J. J. and C. A. S. as part of the requirements for the degree of B.Sc.

\section{REFERENCES}

brenner, M., And ames, B. N. 1971. In Metabolic Pathways, ed. H. J. Vogel, Third ed., 5, 349-387. Academic Press, London and New York. 
BUKHARI, A. I., AND TAYLOR, A. L. 1971. Mutants of Escherichia coli with a growth requirement for either lysine or pyridoxine. J. Bact., 105, 988-998.

MLLER, J. H. 1972. Experiments in Molecular Genetics. Cold Spring Harbor Laboratory, pp. 201-205.

SMrTH, D. A. 1961. Some aspects of the genetics of methionine-less mutants of Salmonella typhimurium. 7. Gen. Microbiol., 24, 335-353.

TAYLOR, A. L., AND TROTTER, C. D. 1972. Linkage map of Escherichia coli strain K12. Bact. Rev. 504-524.

\title{
MALE PARTHENOGENESIS IN TETRAPLOID JOB'S TEARS
}

\author{
PANUGANTI N. RAO \\ Department of Botany, Andhra University, Waltair, India
}

Received 4.xii.73

\begin{abstract}
SUMMARY
Male parthenogenesis was discovered in induced autotetraploid Job's tears, utilising a genetic marker for leaf hairiness, in natural crosses between recessive tetraploids and dominant diploids. In a progeny raised from seeds harvested from the diploid dominant parent one plant showed the recessive character of the tetraploid parent but diploid chromosome number indicating that this was derived through androgenesis in the tetraploid.
\end{abstract}

\section{INTRODUCTION}

Although the occurrence of male parthenogenesis has often been reported in diploid species (Kimber and Riley, 1963; Magoon and Khanna, 1963; Chase, 1969), information on its occurrence in autotetraploids is extremely scarce being restricted to the report of Davies (1958) in autotetraploid barley. In the present investigation, utilisation of genetic markers has afforded an opportunity to identify unexpectedly this apparently rare event in induced autotetraploid Job's tears (Coix lacryma-jobi L.) in an experiment conducted for quite a different purpose.

\section{Experimental materials}

Coix, like other Maydeae, is monoecious and naturally cross-pollinated. A strain of diploid Job's tears $(2 n=20)$, originally collected from plants that ran wild in the University Campus, and its colchicine induced autotetraploid $(4 n=40)$ are homozygous for certain qualitative characters (Campus Wild strain, table 1). These and another true-breeding strain $(2 n=20)$ with contrasting characters (Anantagiri strain, table 1), originally obtained from Anantagiri from a small colony of plants growing submerged along the margins of a hill stream at an altitude of 1000 metres, constituted the materials for this study.

Genetic analysis of the qualitative characters in crosses between the two contrasing diploids showed that purple seedling base and purple style are dominant over green seedling base and white style respectively and hairy leaf is incompletely dominant over glabrous leaf with the $F_{1}$ exhibiting short hairs (Venkateswarlu and Rao, unpublished). 